\title{
Spinocerebellar ataxia type 41
}

INSERM

\section{Source}

INSERM. (1999). Orphanet: an online rare disease and orphan drug data base.

Spinocerebellar ataxia type 41. ORPHA:458798

Spinocerebellar ataxia type 41 is a rare autosomal dominant cerebellar ataxia type III disorder characterized by adult-onset progressive imbalance and loss of coordination associated with an ataxic gait. Mild atrophy of the cerebellar vermis has been reported on brain magnetic resonance imaging. 